\title{
Weight Analysis of Influence Factors and Potential Evaluation Method for Chemical Combination Flooding
}

\author{
LIU Zhaoxia, ${ }^{1, *}$, WANG Qiang ${ }^{1}$, MA Desheng ${ }^{1}$, Gaoming $^{1}$, LIU Wanlu ${ }^{1}$ \\ ${ }^{1}$ State Key Laboratory of EOR, RIPED, No.20 Xueyuan Road, Haidian District, Beijing China
}

\begin{abstract}
In this paper, the weight coefficient of influencing factors for chemical combination flooding is determined by using grey correlation theory. A calculation method for comprehensive evaluation score of chemical combination flooding is established. The influence factor grading and weight grading are combined in this method. By collecting and analysing chemical combination flooding field tests, a prediction method for chemical combination flooding is established by the exponential regression. It reflects the relationship between EOR of the chemical combination flooding and the comprehensive evaluation score. The new method is applied in 6 different reservoirs to evaluate the effect of chemical flooding. The new method determines the weight coefficient of influence factors for chemical combination flooding. It can quickly predict EOR factor of chemical flooding to provide a basis for chemical flooding planning in the field.
\end{abstract}

\section{Introduction}

Chemical combination flooding is the major EOR technology mainly applied in China after polymer flooding. Field application successfully in Daqing, Shengli and Xinjiang oilfields shows a much higher enhanced oil recovery than polymer flooding. In Daqing, enhanced recovery of ASP flooding is generally higher than $18 \%{ }^{[1]}$, which has a quite important effect on the stable oil production. Analysis of influence factors for chemical flooding is usually qualitative based on the numerical simulation. There is nearly no research on the quantitative weight coefficient of influence factors for chemical flooding. In the study of applicability of chemical flooding, it is usually necessary to determine the weight coefficient of different influencing factors to calculate the comprehensive evaluation value and potential of chemical flooding. In this paper, 8 factors are selected as main parameters by analysing influence factors of chemical flooding. Grey relational theory is used in the paper to calculate weight coefficients of 8 key factors by analysing reservoir parameters of 17 chemical flooding field tests. Considering weight coefficients and the score of key influence factors, a comprehensive evaluation factor for chemical flooding is determined. The relationship between comprehensive evaluation factor and enhanced oil recovery of chemical combination flooding is established in the paper. It can quickly predict development potential of chemical flooding for all kinds of reservoirs. Also it is helpful to do the chemical flooding planning.

\section{Gray relational analysis methods}

\footnotetext{
* Corresponding author: zhaoxliu@163.com
}

Gray relational analysis is a multi-factor comparative analysis method ${ }^{[2]}$, and the specific steps are as follows:

\subsection{Determine the analysis sequence}

In order to evaluate the relationship between the target and its influencing factors, it is necessary to select an index as the main factor to reflect the characteristics of the target. The sequence of the main factor data arranged in a certain order is called the gray associated parent sequence, like

$\left\{X_{t}^{0}(0)\right\}, t=1,2,3, \cdots, n$

The sequence of the sub-factors that affect the target data arranged in order of the parent sequence is called the gray relational analysis sub-sequence. If the target has $\mathrm{m}$ sub-factors, the sub-sequence can be written as:

$\left\{\mathrm{X}_{t}^{0}(i)\right\}, t=1,2,3, \cdots, n ; i=1,2,3, \cdots, m$

According to the obtained parent sequence and subsequence, the following raw data matrix can be constructed:

$$
X^{0}(0)=\left[\begin{array}{llrr}
X_{1}^{0}(0) & X_{1}^{0}(1) & \ldots & X_{1}^{0}(m) \\
X_{2}^{0}(0) & X_{2}^{0}(1) & \ldots & X_{2}^{0}(m) \\
\ldots & \ldots & \ldots & \ldots \\
X_{n}^{0}(0) & X_{n}^{0}(1) & \ldots & X_{n}^{0}(m)
\end{array}\right]
$$

\subsection{Dimensionless variable sequence}


The commonly used non-dimensional methods are averaging method, initial value method.

\subsection{Difference sequence, maximum difference and minimum difference}

The absolute difference between the corresponding sequence of the parent sequence and the subsequence is calculated to form an absolute difference matrix. The maximum difference and the minimum difference in the absolute difference matrix are the maximum difference and the minimum difference.

\subsection{Calculate the correlation coefficient}

The data of the absolute difference array is transformed as follows to obtain the correlation coefficient matrix.

$$
\xi_{0 i}(k)=\frac{\Delta(\min )+\rho \Delta(\max )}{\Delta_{0 i}(k)+\rho \Delta(\max )}
$$

In the formula (4), $\xi \mathrm{i}, 0$ is the gray correlation coefficient between parent sequence and subsequence. $\rho$ is the resolution factor. $X_{t}^{1}(i)$ is standardized evaluation index value. $\Delta_{\mathrm{t}}(i, 0)=\left|X_{t}^{1}(i)-X_{t}^{1}(0)\right|$, it is the absolute difference between the main factor and subsequence at the same observation point. $\Delta \min =\min _{t} \min _{i}\left|X_{t}^{1}(i)-X_{t}^{1}(0)\right|$, it is the minimum absolute difference between the main factor and the sub-factors at the same observation point; $\Delta \max =\max _{t} \max _{i}\left|X_{t}^{1}(i)-X_{t}^{1}(0)\right|$ , it the maximum absolute difference between the main factor and the sub-factors at the same observation point.

In order to reduce the influence of data distortion caused by over-largeness of and improve the difference of gray relational coefficient of each evaluation index, in formula (4) it introduces the resolution coefficient $\rho$, and the value interval is generally $[0.1,1]$. In this paper, it is set to $0.5^{[3]}$.

Gray relational definition is as follows,

$$
r_{i, 0}=\frac{1}{n} \sum_{t=1}^{n} \xi_{i, 0}
$$

$\mathrm{N}$ represents the length of the sequence, that is, the number of parameters of each evaluation index, the gray correlation degree of each evaluation index. Note: The gray degree of association is bounded and closer to 1 , indicating that this sub-factor has a greater effect on the main factor and vice versa.

\subsection{Calculate the correlation}

The correlation between the mother sequence and the subsequence is reflected by $\mathrm{M}$ correlation coefficients, and the correlation between $\mathrm{X}_{\mathrm{i}}$ and $\mathrm{X}_{0}$ can be obtained by averaging.

$$
\mathrm{a}_{i}=\frac{1}{m} \sum_{i-1}^{m} r_{i, 0}
$$

ai is the weight coefficient of each evaluation index.

\subsection{Make an order for the correlation coefficients}

The correlation degree between each sub-sequence and the parent sequence is sorted from largest to smallest. The higher the degree of correlation, the higher the degree of influence of the sub-sequence on the parent sequence is.

\section{Potential Evaluation Method for Chemical Combination Flooding}

\subsection{Selection of key influence factors for chemical combination flooding}

The influence factors of chemical combination flooding are mainly divided into two aspects. One is reservoir factors such as reservoir and rock type, physical property parameters of reservoir and physical properties of formation fluids. These factors are both objective and invariable parameters. The other is injecting parameters, including chemical composition and concentration, injection rate and injection rate, etc. These parameters are usually optimized according to reservoir conditions. Therefore, the paper mainly chooses the objective parameters to analyse as the key influencing factors. The reservoir parameters will have an effect, but the law is different, the specific analysis is in Table 1.

\begin{tabular}{|c|c|c|c|}
\hline NO. & Parameters & Unit & Effect on chemical flooding \\
\hline 1 & $\begin{array}{c}\text { Average } \\
\text { permeability }\end{array}$ & $\begin{array}{c}10 \\
{ }^{3} \mu \mathrm{m}^{2}\end{array}$ & $\begin{array}{l}\text { Affect the injection ability of the combination } \\
\text { flooding system and injection speed, the higher } \\
\text { the permeability, the better the injection }\end{array}$ \\
\hline 2 & Reservoir depth & $\mathrm{m}$ & $\begin{array}{l}\text { The deeper the reservoir depth is, the higher the } \\
\text { reservoir temperature is; the impact of reservoir } \\
\text { depth on the combination flooding is nearly the } \\
\text { same with temperature. When the reservoir } \\
\text { depth is too low, the fracture pressure of the } \\
\text { reservoir is low and there may be a risk of } \\
\text { reservoir damage because of increasing } \\
\text { injection pressure }\end{array}$ \\
\hline 3 & $\begin{array}{l}\text { Reservoir } \\
\text { temperature }\end{array}$ & ${ }^{\circ} \mathrm{C}$ & $\begin{array}{l}\text { It mainly affects the chemical combination } \\
\text { system viscosity and the interfacial tension. } \\
\text { With the temperature increasing, the } \\
\text { development effect of chemical flooding will } \\
\text { be worse. }\end{array}$ \\
\hline 4 & $\begin{array}{l}\text { Reservoir water } \\
\text { salinity }\end{array}$ & $\mathrm{mg} / \mathrm{L}$ & $\begin{array}{l}\text { Mainly affects the viscosity of the composite } \\
\text { system. High water salinity may reduce } \\
\text { viscosity of chemical flooding system and get a } \\
\text { worse development effect }\end{array}$ \\
\hline 5 & $\mathrm{Ca}^{2+} \& \mathrm{Mg}^{2+}$ & $\mathrm{mg} / \mathrm{L}$ & $\begin{array}{l}\text { Polycondensation occurs between the polymer } \\
\text { molecules and makes the molecular chain } \\
\text { shorter, directly decreases the solution viscosity }\end{array}$ \\
\hline 6 & VDP & - & $\begin{array}{l}\text { High VDP shows higher reservoir } \\
\text { heterogeneity. It mainly affects the sweeping } \\
\text { efficiency of chemical flooding. }\end{array}$ \\
\hline 7 & $\begin{array}{l}\text { Reservoir oil } \\
\text { viscosity }\end{array}$ & $\mathrm{mPa} \cdot \mathrm{s}$ & $\begin{array}{l}\text { It has an effect on mobility ratio between } \\
\text { displacing and displaced phases. }\end{array}$ \\
\hline 8 & Oil density & - & $\begin{array}{l}\text { It has a similar impact on chemical flooding } \\
\text { with the crude oil viscosity. }\end{array}$ \\
\hline
\end{tabular}

Table 1 Influence factors analysis of chemical combination flooding 


\subsection{Calculation of weight coefficients of key influence factors for combination flooding}

Nine basic parameters of the 17 chemical flooding reservoirs in China were collected and analysed in Table
$2^{[4]-[13]}$. The parent sequence is enhanced oil recovery, and other 8 parameter are sub-sequences that affect combination flooding field application. According to the gray relational theory, nine basic parameters are treated standardized, as shown in Table 3.

Table 2 Reservoir parameters of chemical flooding field tests

\begin{tabular}{|c|c|c|c|c|c|c|c|c|c|}
\hline Block & $\begin{array}{c}\text { EOR } \\
(\%)\end{array}$ & $\begin{array}{c}\mathrm{K} \\
\left(\mu \mathrm{m}^{2}\right)\end{array}$ & $\begin{array}{c}\text { Depth } \\
(\mathrm{m})\end{array}$ & $\begin{array}{c}\mathrm{T} \\
\left({ }^{\circ} \mathrm{C}\right)\end{array}$ & $\begin{array}{c}\text { Salinity } \\
(\mathrm{mg} / \mathrm{L})\end{array}$ & $\begin{array}{c}\mathrm{Ca}^{2+} \& \\
\mathrm{Mg}^{2+} \\
(\mathrm{mg} / \mathrm{L})\end{array}$ & VDP & $\begin{array}{c}\mu_{\mathrm{o}} \\
(\mathrm{mPa} \cdot \mathrm{s})\end{array}$ & $\rho_{\mathrm{o}}\left(\mathrm{g} / \mathrm{cm}^{3}\right)$ \\
\hline ZQXB & 21.40 & 0.509 & 980 & 42.3 & 6650 & 15 & 0.559 & 9.30 & 0.865 \\
\hline XW & 25.00 & 0.589 & 987 & 49.8 & 7478 & 25 & 0.638 & 6.70 & 0.850 \\
\hline XER & 19.60 & 0.658 & 985 & 49.8 & 7478 & 23 & 0.780 & 6.70 & 0.853 \\
\hline BYDX & 21.37 & 0.512 & 1052 & 42.3 & 5611 & 22 & 0.700 & 8.30 & 0.860 \\
\hline XJJB & 23.24 & 0.567 & 960 & 42.3 & 6700 & 20 & 0.550 & 8.40 & 0.860 \\
\hline XRZ & 18.05 & 0.404 & 981 & 49.8 & 7478 & 21 & 0.758 & 6.70 & 0.856 \\
\hline NW & 18.10 & 0.501 & 1052 & 49.4 & 4287 & 15 & 0.660 & 7.40 & 0.850 \\
\hline BYDD & 18.42 & 0.670 & 982 & 42.4 & 5611 & 22 & 0.510 & 8.20 & 0.860 \\
\hline BSX & 18.22 & 0.800 & 990 & 43.0 & 6475 & 14 & 0.630 & 9.60 & 0.865 \\
\hline LBD & 20.30 & 0.676 & 1052 & 45.0 & 7150 & 22 & 0.660 & 10.30 & 0.870 \\
\hline BRD & 18.30 & 0.396 & 989 & 45.5 & 6475 & 14 & 0.670 & 8.60 & 0.860 \\
\hline NL & 18.50 & 0.437 & 995 & 49.4 & 4718 & 15 & 0.690 & 7.40 & 0.850 \\
\hline BRX & 24.70 & 0.503 & 980 & 43.0 & 6475 & 14 & 0.610 & 9.60 & 0.880 \\
\hline ERZ & 23.15 & 0.674 & 1160 & 22.0 & 7000 & 75 & 0.860 & 9.60 & 0.856 \\
\hline QZKX & 20.50 & 1.542 & 1146 & 34.4 & 10022 & 66 & 0.700 & 5.13 & 0.858 \\
\hline GD & 13.40 & 3.818 & 1270 & 65.0 & 5508 & 45 & 0.818 & 41.25 & 0.930 \\
\hline GDXQ & 12.04 & 1.520 & 1250 & 69.0 & 6864 & 143 & 0.838 & 70.00 & 0.950 \\
\hline
\end{tabular}

Table 3 Reservoir parameters standardization of chemical combination flooding test

\begin{tabular}{|c|c|c|c|c|c|c|c|c|c|}
\hline NO. & $\begin{array}{l}\text { EOR } \\
(\%)\end{array}$ & $\underset{\left(\mu \mathrm{m}^{2}\right)}{\mathrm{K}}$ & $\begin{array}{l}\text { Depth } \\
\text { (m) }\end{array}$ & $\begin{array}{c}\mathrm{T} \\
\left({ }^{\circ} \mathrm{C}\right)\end{array}$ & $\begin{array}{l}\text { Salinity } \\
(\mathrm{mg} / \mathrm{L})\end{array}$ & $\begin{array}{c}\mathrm{Ca}^{2+} \& \\
\mathrm{Mg}^{2+} \\
(\mathrm{mg} / \mathrm{L}) \\
\end{array}$ & VDP & $\begin{array}{c}\mu_{\mathrm{o}} \\
(\mathrm{mPa} \cdot \mathrm{s})\end{array}$ & $\rho_{o}\left(\mathrm{~g} / \mathrm{cm}^{3}\right)$ \\
\hline 1 & 0.856 & 0.133 & 0.228 & 0.387 & 0.336 & 0.895 & 0.350 & 0.867 & 0.090 \\
\hline 2 & 1.000 & 0.154 & 0.223 & 0.278 & 0.254 & 0.825 & 0.258 & 0.904 & 0.105 \\
\hline 3 & 0.784 & 0.172 & 0.224 & 0.278 & 0.254 & 0.839 & 0.093 & 0.904 & 0.102 \\
\hline 4 & 0.855 & 0.134 & 0.172 & 0.387 & 0.440 & 0.846 & 0.186 & 0.881 & 0.095 \\
\hline 5 & 0.930 & 0.149 & 0.244 & 0.387 & 0.331 & 0.860 & 0.360 & 0.880 & 0.095 \\
\hline 6 & 0.722 & 0.106 & 0.228 & 0.278 & 0.254 & 0.857 & 0.119 & 0.904 & 0.099 \\
\hline 7 & 0.724 & 0.131 & 0.172 & 0.284 & 0.572 & 0.895 & 0.233 & 0.894 & 0.105 \\
\hline 8 & 0.737 & 0.175 & 0.227 & 0.386 & 0.440 & 0.846 & 0.407 & 0.883 & 0.095 \\
\hline 9 & 0.729 & 0.210 & 0.220 & 0.377 & 0.354 & 0.902 & 0.267 & 0.863 & 0.089 \\
\hline 10 & 0.812 & 0.177 & 0.172 & 0.348 & 0.287 & 0.846 & 0.233 & 0.853 & 0.084 \\
\hline 11 & 0.732 & 0.104 & 0.221 & 0.341 & 0.354 & 0.902 & 0.221 & 0.877 & 0.095 \\
\hline 12 & 0.740 & 0.114 & 0.217 & 0.284 & 0.529 & 0.895 & 0.198 & 0.894 & 0.105 \\
\hline 13 & 0.988 & 0.132 & 0.228 & 0.377 & 0.354 & 0.902 & 0.291 & 0.863 & 0.074 \\
\hline 14 & 0.926 & 0.177 & 0.087 & 0.681 & 0.302 & 0.476 & 0.000 & 0.863 & 0.099 \\
\hline 15 & 0.820 & 0.404 & 0.098 & 0.501 & 0.000 & 0.538 & 0.186 & 0.927 & 0.097 \\
\hline 16 & 0.536 & 1.000 & 0.000 & 0.058 & 0.450 & 0.685 & 0.049 & 0.411 & 0.021 \\
\hline 17 & 0.482 & 0.398 & 0.016 & 0.000 & 0.315 & 0.000 & 0.026 & 0.000 & 0.000 \\
\hline
\end{tabular}

According to the formula (4), the correlation coefficients between eight reservoir parameters and the enhanced recovery of combination flooding are calculated, as shown in Table 4. 
Table 4 Correlation coefficient between reservoir parameters and enhanced oil recovery

\begin{tabular}{|c|c|c|c|c|c|c|c|c|c|}
\hline NO. & $\begin{array}{c}\text { EOR } \\
(\%)\end{array}$ & $\begin{array}{c}\mathrm{K} \\
\left(\mu \mathrm{m}^{2}\right)\end{array}$ & $\begin{array}{l}\text { Depth } \\
\text { (m) }\end{array}$ & $\begin{array}{c}\mathrm{T} \\
\left({ }^{\circ} \mathrm{C}\right)\end{array}$ & $\begin{array}{l}\text { Salinity } \\
(\mathrm{mg} / \mathrm{L})\end{array}$ & $\begin{array}{c}\mathrm{Ca}^{2+} \& \\
\mathrm{Mg}^{2+} \\
(\mathrm{mg} / \mathrm{L})\end{array}$ & VDP & $\begin{array}{c}\mu_{\mathrm{o}} \\
(\mathrm{mPa} \cdot \mathrm{s})\end{array}$ & $\rho_{o}\left(\mathrm{~g} / \mathrm{cm}^{3}\right)$ \\
\hline 1 & 1.000 & 0.445 & 0.846 & 0.730 & 0.533 & 0.891 & 0.818 & 1.000 & 0.767 \\
\hline 2 & 1.000 & 0.402 & 0.740 & 0.559 & 0.429 & 0.600 & 0.658 & 0.749 & 0.694 \\
\hline 3 & 1.000 & 0.492 & 0.904 & 0.699 & 0.527 & 0.843 & 0.687 & 0.698 & 0.824 \\
\hline 4 & 1.000 & 0.445 & 0.803 & 0.731 & 0.601 & 1.000 & 0.701 & 0.942 & 0.771 \\
\hline 5 & 1.000 & 0.423 & 0.801 & 0.670 & 0.492 & 0.804 & 0.768 & 0.868 & 0.727 \\
\hline 6 & 1.000 & 0.490 & 0.969 & 0.753 & 0.564 & 0.664 & 0.743 & 0.595 & 0.869 \\
\hline 7 & 1.000 & 0.501 & 0.911 & 0.756 & 0.882 & 0.606 & 0.831 & 0.613 & 0.873 \\
\hline 8 & 1.000 & 0.517 & 0.952 & 0.851 & 0.701 & 0.712 & 1.000 & 0.651 & 0.854 \\
\hline 9 & 1.000 & 0.540 & 0.954 & 0.850 & 0.631 & 0.602 & 0.858 & 0.672 & 0.856 \\
\hline 10 & 1.000 & 0.481 & 0.835 & 0.734 & 0.530 & 0.907 & 0.761 & 0.895 & 0.792 \\
\hline 11 & 1.000 & 0.484 & 0.952 & 0.805 & 0.629 & 0.607 & 0.814 & 0.653 & 0.858 \\
\hline 12 & 1.000 & 0.486 & 0.939 & 0.742 & 0.798 & 0.630 & 0.789 & 0.638 & 0.860 \\
\hline 13 & 1.000 & 0.398 & 0.751 & 0.623 & 0.475 & 0.764 & 0.683 & 0.688 & 0.684 \\
\hline 14 & 1.000 & 0.434 & 0.703 & 1.000 & 0.479 & 0.361 & 0.571 & 0.829 & 0.731 \\
\hline 15 & 1.000 & 0.606 & 0.775 & 0.892 & 0.403 & 0.478 & 0.723 & 0.725 & 0.795 \\
\hline 16 & 1.000 & 0.578 & 0.927 & 0.722 & 1.000 & 0.639 & 0.834 & 0.688 & 0.966 \\
\hline 17 & 1.000 & 1.000 & 1.000 & 0.719 & 0.860 & 0.345 & 0.863 & 0.349 & 1.000 \\
\hline
\end{tabular}

According to the formula (6), the weight coefficients of the 8 influence factors are calculated as follows: 0.513 , $0.868,0.755,0.620,0.674,0.771,0.721$ and 0.819 , and the influence factors are sorted according to the weight coefficient: reservoir depth> crude oil density> coefficient of variation of permeability $>$ reservoir temperature $>$ viscosity of underground crude oil $>$ divalent ion content $>$ formation water salinity $>$ average permeability.

\subsection{Establishment \& application of potential evaluation method for Chemical combination flooding}

The comprehensive evaluation factor of the chemical combination flooding is the weighted average of the product of each influential factor score and its weight coefficient, that is,

$$
Z=\sum_{i=1}^{8} f(i) \times w(i) / \sum_{i=1}^{8} w(i)
$$

In formula (7), $\mathrm{Z}$ is comprehensive evaluation factor of combination flooding; $f(i)$ is the score of the $i^{\text {th }}$ influencing factor; w (i) is weight coefficient of the $\mathrm{i}^{\text {th }}$ influencing factor.

According to the parameter screening standards in the literature ${ }^{[14]}$, comprehensive evaluation factors of 17 chemical combination flooding field tests are calculated based on formula (7) in Figure 1. Using exponential regression method, the relationship between comprehensive evaluation factor and enhanced oil recovery is built to predict development potential of chemical combination flooding in formula (8).

$$
E O R=8.694 e^{1.898 Z}
$$

In formula (8), EOR is the enhanced oil recovery, and $\mathrm{Z}$ is the comprehensive evaluation factor of combination flooding.

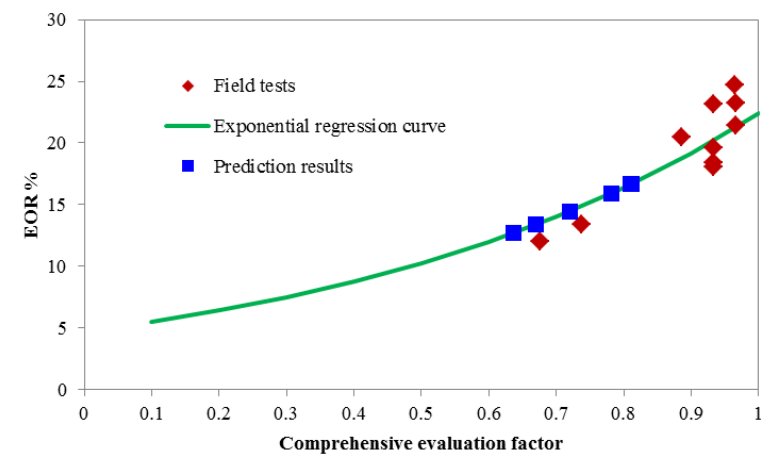

Fig. 1. Chemical flooding development potential prediction curve \& its application

Table 5 Evaluation result of chemical flooding in 6 reservoirs

\begin{tabular}{|c|c|c|c|c|c|c|c|c|c|c|}
\hline Blocks & $\begin{array}{c}\mathrm{K} \\
\left(\mu \mathrm{m}^{2}\right)\end{array}$ & $\begin{array}{c}\text { Depth } \\
(\mathrm{m})\end{array}$ & $\begin{array}{c}\mathrm{T} \\
\left({ }^{\circ} \mathrm{C}\right)\end{array}$ & $\begin{array}{c}\text { Salinity } \\
(\mathrm{mg} / \mathrm{L})\end{array}$ & $\begin{array}{c}\mathrm{Ca}^{2+} \& \\
\mathrm{Mg}^{2+} \\
(\mathrm{mg} / \mathrm{L})\end{array}$ & $\mathrm{VDP}$ & $\begin{array}{c}\mu_{\mathrm{o}} \\
(\mathrm{mPa} \cdot \mathrm{s})\end{array}$ & $\begin{array}{c}\rho_{\mathrm{o}} \\
\left(\mathrm{g} / \mathrm{cm}^{3}\right)\end{array}$ & $\mathrm{Z}$ & $\begin{array}{c}\text { EOR } \\
\%\end{array}$ \\
\hline
\end{tabular}




\begin{tabular}{|c|c|c|c|c|c|c|c|c|c|c|}
\hline $\begin{array}{c}\text { B in } \\
\text { Xinjiang }\end{array}$ & 141 & 2185 & 42 & 6426 & 58.6 & 0.82 & 8.2 & 0.875 & 0.813 & 16.7 \\
\hline $\begin{array}{c}\text { L in } \\
\text { Xinjiang }\end{array}$ & 1126 & 1168 & 37 & 8154 & 147 & 0.72 & 49.7 & 0.883 & 0.810 & 16.6 \\
\hline $\begin{array}{c}\text { S in } \\
\text { Changqing }\end{array}$ & 70.25 & 1564 & 50 & 17000 & 400 & 0.66 & 2.3 & 0.85 & 0.720 & 14.5 \\
\hline H in Sudan & 2745 & 1615 & 80 & 4903 & 260 & 0.72 & 19 & 0.875 & 0.782 & 15.9 \\
\hline $\begin{array}{c}\text { M in } \\
\text { Ecuador }\end{array}$ & 3847 & 2118 & 88 & 15500 & 270 & 0.70 & 8.5 & 0.84 & 0.637 & 12.7 \\
\hline G in Jidong & 1530 & 1850 & 64 & 2650 & 150 & 0.74 & 90.34 & 0.957 & 0.669 & 13.4 \\
\hline
\end{tabular}

The prediction result shows the order for chemical combination flooding application: $\mathrm{B}$ reservoir and L reservoir in Xinjiang, $\mathrm{H}$ reservoir in Sudan, $\mathrm{S}$ reservoir in Changqing, $G$ reservoir in Jidong and $M$ reservoir in Ecuador. Among these reservoirs, B, L and $\mathrm{H}$ reservoirs are more suitable for chemical combination flooding than other reservoirs. Chemical flooding EOR in these three reservoirs are higher than $16 \%$. Due to a lower EOR factor, $M$ and $G$ reservoirs are not applicable for chemical flooding.

\section{Summary}

The gray relational theory was used to determine the weight coefficients of influence factors for chemical compound flooding. The order of the influence factor weight coefficients was reservoir depth $>$ oil density $>$ VDP $>$ reservoir temperature $>$ reservoir oil viscosity $>$ $\mathrm{Ca}^{2+} \& \mathrm{Mg}^{2+}>$ water salinity $>$ average permeability.

Considering the influencing factors and their weight coefficients, a calculation method of the comprehensive evaluation factor for chemical compound flooding is established.

Using exponential regression method, the new potential prediction method is derived for chemical compound flooding. The new method was applied to evaluate the effect and applicability of chemical compound flooding in six different blocks.

The prediction method proposed in this paper needs a few parameters and is convenient to be used for the rapid evaluation of the feasibility of chemical combination flooding.

\section{Acknowledgements}

This research was financially supported by 2 projects. One is the National Science and Technology Major Project (No.2016ZX05010-005). The other is CNPC science and technology project (NO.2016B-1104).

\section{References}

1. WANG Fenglan, WU Xiaolin, CHEN Guangyu, et al. TECHNICAL PROGRESS OF ALKALINESURFACTANT-POLYMER FLOODING

( ASP ) IN DAQING OILFIELD, Petroleum Geology \& Oilfield Development in Daqing, 2009, 28(5): 154-162
2. XU Honglong, LIU Jian, QIAO Cheng, et al, Application of gray correlative analysis method to reservoir evaluation of Shuanhe oilfield, Reservoir Evaluation and Development, 2015, 5(3): 17-21

3. TU Yi, XIE Chuanli, LIU Chao, et al, Application of Grey Correlation Analysis Method in Reservoir Evaluation of Qingdong Sag, Natural Gas Geoscience, 2012, 23(2): 381-386

4. WANG Qimin, JI Baofa, SUI Jun, et al, Practice and Knowledge of Tertiary Recovery Technique in Daqing Oilfield, Petroleum Geology \& Oilfield Development in Daqing, 2001, 20(4): 1-9

5. YANG Xue, Dynamic Variation Characteristics of ASP Flooding in Beierxi Block in Daqing Oilfield, Inner Mongulia Petrochemical Industry, 2012, (7): 114-116

6. CHENG Jiecheng, WANG Demin, LI Qun, et al, Field test performance of alkaline surfactant polymer flooding in Daqing Oil Field, Acta Petrolei Sinica, 2002, 23(6): 37-40

7. CHENG Jiecheng, LIAO Guangzhi, YANG Zhenyu, et al, PILOT TEST OF ASP FLOODING IN DAQING OILFIELD, Petroleum Geology \& Oilfield Development in Daqing, 2001, 20(2): 4649

8. LI Shikui, ZHU Yan, ZHAO Yongsheng, et al, Evaluation of pilot results of alkali-surfactantpolymer flooding in Daqing Oilfield, Acta Petrolei Sinica, 2005, 26(3): 56-60

9. YANG Shaoju, ZHU Yang, MA Xinyu, et al, Field test of ASP flooding in Gudao Oilfield, Journal of Jianghan Petroleum Institute, 2002, 21(1): 62-63

10. CAO Xulong, SUN Huanquan, JIANG Yanbo, et al, Enlarged Field Test on ASP-Flood at East District of Gudao Oil Field, Oilfield Chemistry, 2002, 19(4): 350-353

11. ZHANG Yigen, WANG Youqi, QU Zhijian, et al, Field test of Guantao reservoir ASP flooding in Gudong Oilfield, Oilfield Chemistry, 1994, 11(2): 143-148

12. ZHAO Changjiu, LU Shouliang, LI Xinfeng, et al, On the effectiveness of increasing oil recovery factors with ASP flooding and polymer flooding under the limit water-cut conditions, Petroleum Exploration and Development, 2007, 34(3): 354358 
13. WANG Yu, QIAO Qi, DONG Ling, et al, Study on of cheap formulations for ASP Flooding expanding Tests in Karamay Oilfield, Oilfield Chemistry, 1999, 16(3): 247-250

14. LIU Zhaoxia, WANG Qiang, SUN Yingying, et al, The research and application of new technological boundaries for polymer flooding, Petroleum Geology and Recovery Efficiency, 2014, 21(2): 2225 